\title{
COMPORTAMENTO DE ACASALAMENTO DE Methona themisto (LEPIDOPTERA: NYMPHALIDAE) EM LABORATÓRIO
}

\author{
Andressa Santoro', Gabriela Barone Volce da Silva², Satiko Nanya \\ ${ }^{1}$ Acadêmica do curso de Ciências Biológicas, Universidade Estadual de Maringá - UEM. PIC/UEM andressasantoro12@hotmail.com \\ ${ }^{2}$ Acadêmica do curso de Ciências Biológicas, Universidade Estadual de Maringá - UEM. PIC/UEM gabrielabaronevolce@hotmail.com \\ ${ }^{3}$ Orientadora, Doutora, Departamento de Biotecnologia, Genética e Biologia Celular, UEM. Laboratório de Controle Biológico, \\ Morfologia e Citogenética de Insetos. snanya@uem.br
}

\begin{abstract}
RESUMO
Methona themisto é bastante conhecida na região sul e sudeste do Brasil, sendo que as lagartas se alimentam de folhas de Brunfelsia sp., conhecidas como "manacá de cheiro" ou "jasmim manacá", presentes em praças e jardins. A maioria dos animais realiza o comportamento de côrte como uma das etapas que antecedem a reprodução. O macho corteja a fêmea a fim de se reproduzir. Ela, por sua vez, escolhe o macho que se mostra mais adaptado ao meio ambiente. Desta forma, o objetivo desta pesquisa foi realizar a criação e manutenção de Methona themisto em laboratório para avaliar o comportamento de acasalamento. A criação foi feita em caixas de polipropileno e manutenção diária no Laboratório de Controle Biológico, Morfologia e Citogenética de Insetos da Universidade Estadual de Maringá. O desenvolvimento completo da Methona themisto levou em torno de 43 dias. $O$ acasalamento ocorreu 10 a 15 dias após a emergência do adulto. O macho fez um ritual para assim obter a atenção da fêmea. Ele começou a ter um voo excitado, fazendo um tipo de "dança" para atrair a fêmea. Em torno de vinte e quatro horas após a cópula, a fêmea estava preparada para começar a fazer as primeiras posturas de ovos - entre quinze e vinte ovos. Um novo acasalamento pode ocorrer em torno de 6 a 8 dias. Assim, é possível concluir que devido ao ciclo de vida ser curto se comparado com outras espécies de Lepidoptera, e o comportamento de côrte e acasalamento ocorrem no interior de cesto telado torna essa espécie viável para serem mantidas no interior de borboletário, visando à preservação da espécie e a Educação ambiental.
\end{abstract}

PALAVRAS-CHAVES: Borboletário; Comportamento de côrte; Cópula; Pré-cópula; Reprodução.

\section{INTRODUÇÃO}

Os insetos representam um grupo muito diverso e dominante dos animais no planeta Terra, compreendem cerca de $59 \%$ de todos os animais do planeta $(751.000$ espécies) e desempenham papel chave nos ecossistemas terrestres (WILSON, 2003). São grandes responsáveis pela dispersão de sementes de plantas, polinização, manutenção de vegetação, uma vez que se alimentam dela, fazem a reciclagem de nutrientes, degradam madeira, participam da decomposição dos cadáveres, servem de alimento para outros animais e também podem ser vetores de doenças e parasitas, controlando populações. (GULLAN; CRANSTON, 2007)

Eles possuem esqueleto externo e são em geral de tamanho pequeno se comparado a outros animais, permitindo assim viver em muitos lugares. A coloração varia desde pardas até cores vibrantes. São seres de sangue frio, sendo vulneráveis a temperatura do meio externo para a realização dos processos fisiológicos. A reprodução do inseto, no geral, é eficaz e o ciclo de vida pode apresentar alterações no desenvolvimento, como por exemplo, as borboletas, ao eclodir o ovo, uma lagarta começa a crescer e após um período, se transforma em uma pupa e só depois em borboleta (TRIPLEHORN; JONNSON, 2011). 
A Ordem Lepidoptera inclui as borboletas juntamente com as mariposas, contendo mais de 11.500 espécies. Na região Neotropical, as borboletas são representadas entre 7.100 (BECCALONI; GASTON, 1995) e 7.900 espécies (HEPPNER, 1991; LAMAS, 2004), cujos adultos normalmente são coloridos e de hábitos diurnos. São reconhecidas por apresentarem escamas nas asas e no corpo e sofrerem metamorfose completa, sendo que na fase jovem as larvas são denominadas de lagartas (TRIPLEHORN; JONNSON, 2011) e na fase adulta, as borboletas dividem-se em duas guildas: as frugívoras, que se alimentam principalmente de caldo de frutas fermentadas, e as nectarívoras, que se alimentam de néctar de fores (DEVRIES, 1987). Além disso, as borboletas também podem sugar seiva fermentada, sais minerais de poças de água, fezes, urina e carcaças de animais em decomposição (FRANCINI, 2010).

Dentre as várias famílias da Ordem Lepidoptera, a Nymphalidae apresenta aproximadamente 6.000 a 8.200 espécies descritas sendo o maior número de espécies, a mais diversa relação com plantas hospedeiras e a maior diversidade de formas larvais. Dentro dessa família encontram-se as borboletas frugívoras (SILVA, 2008). Uma de suas sub-família é o Ithomiinae onde encontra-se as borboletas da espécie Methona themisto. Essa espécie é bastante conhecida na região sul e sudeste do Brasil, sendo que as lagartas se alimentam de folhas de plantas de Brunfelsia sp. (Solanaceae), conhecida popularmente como "manacá de cheiro" ou "jasmim manacá", presente em praças e jardins (RUSZCZYK; NASCIMENTO, 1999). As lagartas de Methona themisto tem coloração preta com listas amarelas a alaranjadas. E as borboletas adultas apresentam asas pretas com detalhes em amarelo e branco (RUSZCZYK; NASCIMENTO, 1999), voam lentamente, sendo facilmente observadas. Quando capturados, os adultos ficam imóveis por alguns segundos ilustrando o curioso fenômeno da tanatose. Os imaturos e adultos de $M$. themisto tem um grande valor estético e educativo para os cidadãos. Apesar de ser um inseto popular, há poucas informações publicadas sobre a biologia, ecologia e a morfologia de $M$. themisto em áreas urbanas, sendo consideradas pragas do manacá de cheiro.

$\mathrm{Na}$ natureza, a reprodução de muitos organismos, é antecipada por uma série de etapas que visam o reconhecimento da espécie e/ou do grau de maturidade sexual, dentre elas o comportamento de côrte, nos quais, na maioria dos casos, os machos se exibem para as fêmeas. Para isso, eles demostram características que os façam parecer que possuem genes melhores que os dos outros indivíduos, convencendo a fêmea de que se ela optar por ele, a sua prole terá mais chance de sobreviver (REIS, 2003). O coito pode ser rápido (alguns minutos) como nas borboletas ou prolongar-se por várias horas. $\mathrm{Na}$ aproximação dos sexos, desempenha papel saliente o odor da secreção das glândulas de certas áreas do corpo, mais ou menos densamente revestidas de escamas especiais (plumulas), situadas na extremidade do abdome das fêmeas, nas asas (androconia), na base do abdome e em outras regiões do corpo dos machos (COSTA LIMA, 1945). Pouco se sabe a respeito dos aspectos reprodutivos em muitas espécies de borboletas, inclusive em Methona themisto. Em lepidópteras esse comportamento se diferencia devido aos obstáculos ambientais presentes como a distância, além do pequeno ciclo de vida e curto período reprodutivo. Além disso, ao longo de sua vida adulta, dependendo da espécie, uma borboleta fêmea pode acasalar-se uma única (monandria) ou várias vezes (poliandria), podendo haver variações quanto a poliandria, ou seja, o número médio de machos com que as fêmeas acasalam diferem entre as espécies. Assim, o objetivo desta pesquisa foi realizar a criação e manutenção de Methona themisto em laboratório para avaliar o comportamento de acasalamento e posterior criação em borboletário visando a preservação da espécie e a Educação ambiental. 
Ovos e lagartas de Methona themisto foram coletados em março de 2018 no campus da Universidade Estadual de Maringá, no munícipio de Maringá, Paraná, localizada a 551 metros de altitude, Latitude: $23^{\circ} 25^{\prime} 38^{\prime \prime}$ Sul Longitude: 51 56' 15" Oeste, com média pluviométrica anual de 1.500 mililitros e média anual de temperatura $21,95^{\circ} \mathrm{C}$ sendo criadas no Laboratório de Controle Biológico, Morfologia e Citogenética de Insetos da Universidade Estadual de Maringá no Bloco H-67, sala 7A, DBC/UEM, a temperatura ambiente em torno de $25^{\circ} \mathrm{C}$ e umidade relativa média de $70 \%$. As posturas de ovos realizadas nos ramos de manacá em cestos telados de 35 centímetros $(\mathrm{cm})$ de largura por $50 \mathrm{~cm}$ de altura, área de 61,25 centímetros cúbicos, foram separadas em potes de polipropileno retangulares de 2 litros e realizada a manutenção da criação. Os potes de criação de ovos e larvas continham ramos da planta hospedeira, Brunfelsia sp.. A manutenção dos potes foi feita diariamente, observando-se as alterações ocorridas durante o desenvolvimento e fazendo anotações para caracterizar o período de cada uma das fases. As pupas foram mantidas também em potes contendo algodão úmido para manter a umidade necessária ao seu desenvolvimento. Ao atingirem a fase adulta foi feito a sexagem dos espécimes. Uma amostra de borboletas, fêmeas e machos foram transferidos para cestos telados, contendo 2 tipos de alimentos, um deles constituído de mel, levedura e água e o outro algodão com açúcar embebido em água, sendo trocado a cada 2 dias e também um ramo de manacá para postura de ovos, e observação diárias para verificar o comportamento de acasalamento e a presença de ovos nas folhas do ramo e anotar se houve alguma mortalidade. Os demais espécimes foram liberados no interior do borboletário sendo feito o monitoramento para análise da viabilidade de Methona themisto em cativeiro. A manutenção do borboletário está sendo feito com a colocação de plantas com flores e pedaços de frutas maduras para alimentação das borboletas e observação da planta hospedeira para verificar a postura de ovos. A documentação fotográfica foi feita utilizando-se câmera fotográfica digital, procedendo a descrição e discussão dos resultados obtidos.

\section{RESULTADOS E DISCUSSÃO}

Durante o período de execução da pesquisa, de março a dezembro de 2018 foram manuseados aproximadamente 60 potes que continham de um a cinco ovos de Methona themisto em cada pote, sendo possível observar o desenvolvimento desde a fase de ovo até a fase adulta.

O desenvolvimento de Methona themisto é holometábola como em outros lepidopteras, ou seja, possui quatro fases, que são ovo, larva ou lagarta, pupa ou crisálida ou casulo e imago ou adulto. Verificou-se que o ovo logo após a postura apresenta coloração esbranquiçada e no final escurece e leva aproximadamente 6 dias até a sua eclosão (Fig. 1A). Já a fase de lagarta é dividida em cinco instares, a cada mudança de instar ocorre a troca da epiderme e juntamente com esta a cápsula cefálica. Em cada instar a cápsula cefálica apresenta um tamanho diferente como pode se ver na Figura 2. Após a eclosão do ovo ocorre o nascimento da larva ou lagarta (Fig. 1B), com aproximadamente 4 milímetros $(\mathrm{mm})$ de comprimento, vermiforme com coloração amarelo e ficando acinzentado à medida que vão crescendo, com aparelho bucal do tipo mastigador, esse primeiro instar tem duração em torno de 4 dias. O segundo instar e terceiro instar larval tem duração de quatro dias cada e caracteriza-se por apresentar 12 listras pretas e amarelas intercaladas ao longo do corpo. O quarto instar tem duração de 5 a 6 dias e a lagarta se alimenta muito. O quinto instar é mais longo e varia de 8 a 10 dias quando a lagarta atinge um tamanho em torno de 60 milímetros. A fase de lagarta leva em torno de 26 dias. A pupa que é o penúltimo estágio imaturo (Fig. 1C) é do tipo obtecta, apresenta coloração amarelo com algumas machas pretas que variam na forma, tamanho e quantidade, leva em média 10 dias. Durante o desenvolvimento da pupa sua coloração escurece gradualmente devido 
a formação das asas que são amareladas com contornos e faixas pretas. Da pupa emerge o inseto adulto ou imago (Fig. 1D). O ciclo de vida, de ovo até a fase adulta leva em média 43 dias. Nos primeiros 50 minutos em contato com o meio exterior, o inseto recém-emergido permanece em repouso sobre sua crisálida realizando a secagem das asas e preparandose para o vôo.
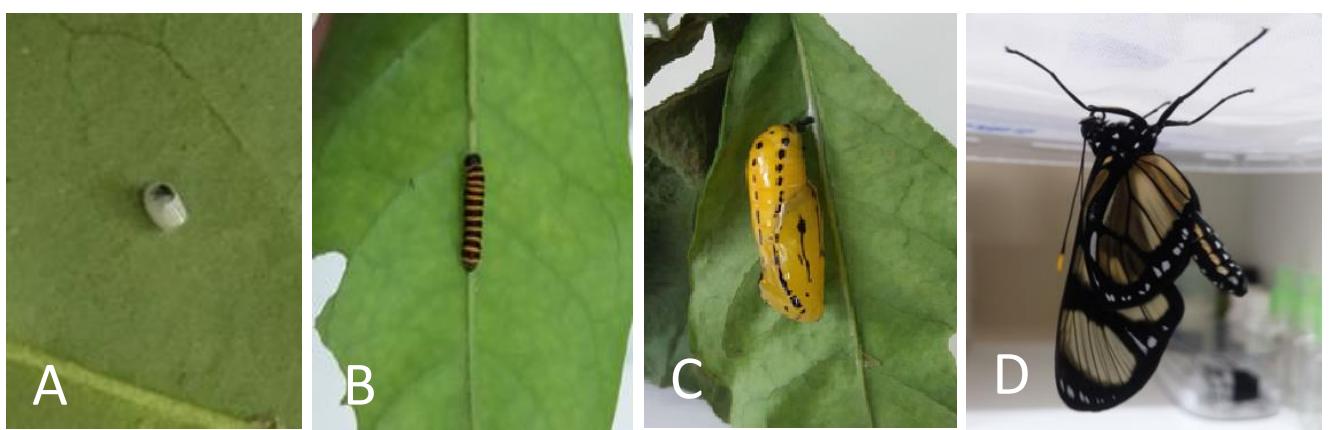

Figura 1- Diferentes fases de Methona themisto. A.Ovo fértil; B. Lagarta de 3 instar; C. Pupa; D. Adulto. $\mathrm{A}=$ Aumento $16 \mathrm{X}$.

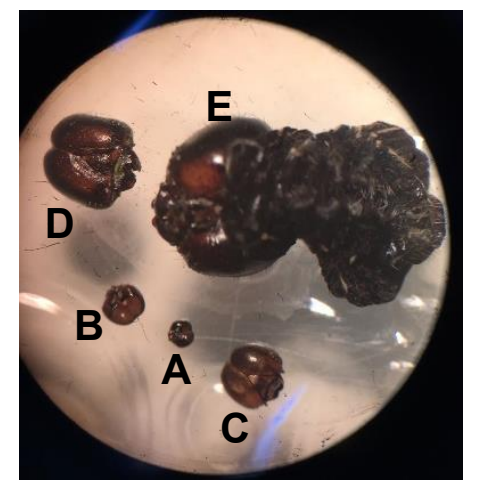

Figura 2- Cápsulas cefálicas de lagartas de Methona themisto. A. $1^{\circ}$ instar; B. $2^{\circ}$ instar; C. $3^{\circ}$ instar; D. $4^{\circ}$ instar; E. 5ํinstar.

Como a maioria dos insetos adultos, os lepidópteros apresentam o corpo dividido em cabeça, tórax e abdômen. Em adultos de Methona themisto, na cabeça estão presentes os apêndices cefálicos e um par de olhos compostos e hemisféricos. Os apêndices cefálicos são representados por um par de antenas, labro, maxilas e lábio. As antenas são longas, clavadas e se encontram localizadas nas margens dorsolaterais do esclerito frontoclipeal. O labro, maxila e lábio constituem o aparelho bucal sugador maxilar exclusivo desses insetos. As maxilas dão origem a espirotromba, apêndice longo e espiralado que se alonga para retirar néctar ou outros fluidos açucarados do interior de plantas e se enrola quando em repouso. No tórax estão articulados os três pares de pernas ambulatórias que não apresentam nenhuma característica evolutiva, ou seja, esses apêndices são utilizados somente para equilíbrio, pois a locomoção principal é feita a partir do voo onde os 2 pares de asas membranosas providas de minúsculas escamas são utilizadas. O segmento final do corpo é o abdômen que se apresenta alongada, delgada, com coloração preta e manchas brancas e amarelas. Através da extremidade posterior do abdômen é possível fazer a sexagem dos indivíduos. A fêmea apresenta uma concavidade na porção final desse segmento e no macho é arredondado sem nenhuma protuberância. O inseto adulto sobrevive em média 47 dias e o tempo médio de vida é em torno de 90 dias a temperatura média no período de $25^{\circ} \mathrm{C}$.

Souza-Junior (2017) analisando o desenvolvimento de Methona themisto verificou que o tempo médio da fase de ovo foi de 6,8 dias, de lagarta 19,8 dias e de pupa 10,9 dias, totalizando um ciclo de vida de aproximadamente 37,4 dias, sendo a média da temperatura 
durante a criação na fase de ovo foi de $21,8^{\circ} \mathrm{C}$, na fase de lagarta foi de $28,3^{\circ} \mathrm{C}$ e na fase de pupa de $28,5^{\circ} \mathrm{C}$. Já Marques, Camargo e Lacerda (2014) obtiveram uma média de 49 dias em seu estudo a temperatura ambiente de aproximadamente $22^{\circ} \mathrm{C}$. Comparando os resultados obtidos de desenvolvimento de ovo até adulto de Methona themisto verificou-se que os resultados de Souza-Junior (2017) têm uma duração menor se comparados a dos de Marques, Camargo e Lacerda (2014). Essas diferenças provavelmente são decorrentes das variações climáticas anuais e dependentes de cada região.

Ao chegarem a fase adulta, machos e fêmeas de Methona themisto (Fig. 3), foram transferidos para um cesto telado para observar o comportamento de cortê para o acasalamento. $\mathrm{O}$ acasalamento ocorreu após 10 a 15 dias quando as borboletas se tornaram sexualmente maduras. Algumas borboletas fêmeas realizaram postura de ovos nas folhas do ramo de manacá de cheiro presentes no interior do cesto, por volta do sétimo dia, porém verificou-se que esses ovos eram inférteis (Fig. 4), ou seja, não ocorreu o desenvolvimento embrionário, e o ovo estava vazio, apresentando-se transparente, diferente dos ovos férteis que são de um aspecto branco leitoso.

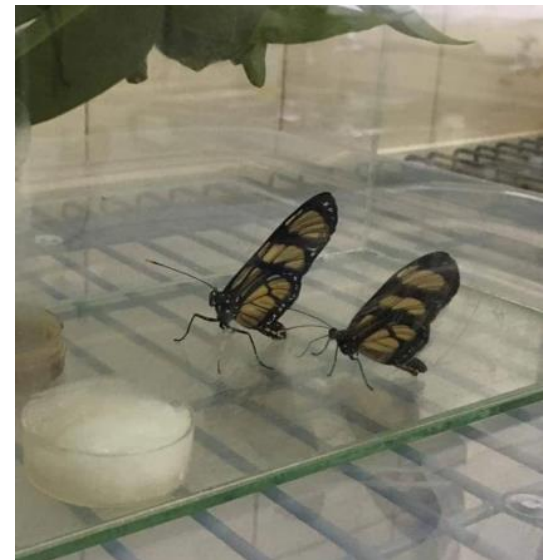

Figura 3- Methona themisto adulto.

A esquerda fêmea e a direita macho.

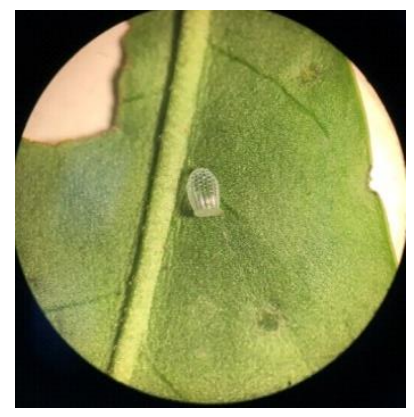

Figura 4- Ovos inférteis. Aumento de 16x.

Para que o acasalamento ocorresse o macho realizou um ritual para obter a atenção da fêmea. Em geral, o macho realiza vôo tranquilo, mas para atrair a fêmea se torna rápido e excitado, fazendo um tipo de "dança" próximo a fêmea, esse ritual teve duração de algumas horas. Após esse ritual ocorreu a aproximação entre o macho e a fêmea, cujas glândulas secretam feromônios que permitem a fêmea aceitar a cópula. Para ocorrer a cópula, o macho encurva o seu abdômen para tocar na extremidade do abdômen da fêmea. Assim, com o acoplamento entre as genitálias, o macho gira o seu corpo para ficar no sentido contrário da fêmea (Fig. 5). Durante a cópula não ocorreu muitos movimentos, eles ficaram em repouso e as asas fechadas até o final da cópula, que normalmente dura mais de cinco horas (Fig. 5). Após a cópula, a união entre ambos foi desfeita e verificou-se o 
inchaço do abdômen das fêmeas e após cerca de vinte e quatro horas começou a postura de ovos nas folhas da planta hospedeira. Em geral, a borboleta fêmea de M. themisto, encurva o seu abdômen na parte abaxial das folhas e realiza a postura dos ovos, de quinze a vinte ovos (Fig. 6). Entre as posturas há uma pausa de 5 a 10 minutos, não realizando de uma só vez. Nos cestos telados, observou-se que as fêmeas realizam a postura de mais de um ovo por folha, sendo que na natureza geralmente é um ovo apenas. Um novo acasalamento ocorreu com as borboletas, após 6 a 8 dias onde se inicia um novo ciclo de reprodução. Foi possível observar que normalmente a cópula se dá com o mesmo macho, o que foi verificado quando havia mais de um macho no cesto de acasalamento.

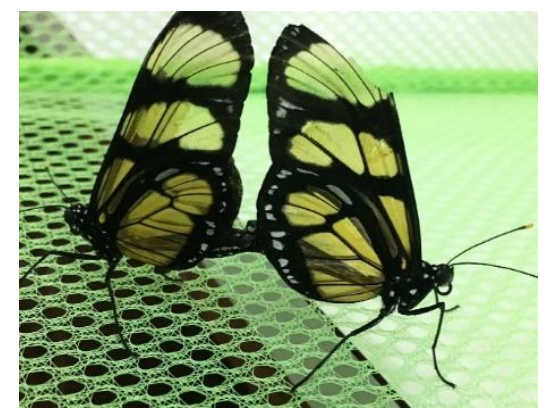

Figura 5- Acasalamento entre borboletas Methona themisto.

Observar a posição das asas durante a cópula.

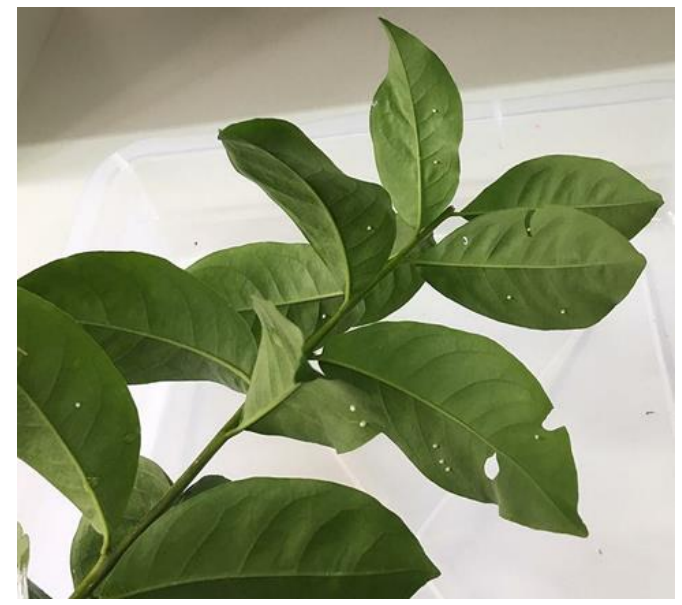

Figura 6. Postura dos ovos nas folhas da planta hospedeira. Variação do numero de ovos por folha.

O comportamento de côrte em lepidópteras tem a mesma finalidade daquelas em outros animais. Segundo Reis (2003, p. 8) os lepidópteros machos procuram conquistar a fêmea para garantir sua reprodução, da mesma forma a fêmea escolhe o macho que se encontra melhor adaptado ao meio, a fim de que suas características passem para prole através de seus genes. Na mesma classe esse comportamento difere de uma família para outra, de um gênero para outro e assim por diante (REIS, 2003, p. 11). De acordo com Lamy (1997) após o vôo, o macho é atraído por feromônio liberado pela fêmea, que o leva ao encontro de sua possível parceira e ao chegar próximo dela, esse macho libera outro feromônio que inibe a secreção do feromônio de atração da fêmea. Sbordoni e Forestieiro (1984) relata que a liberação de feromônio faz com que outros machos não se aproximem, bem como nenhum predador perceba o odor. Segundo Boggs e Gilbert (1979) durante a cópula o espermatóforo, estrutura produzida pelo macho e que contêm os espermatozoides, é transferido para fêmea e, de acordo com Silva (2009) apresenta em sua composição algumas substâncias que podem ser muito importantes para a fêmea. 
Quanto ao acasalamento, a espécie Methona themisto pode acasalar mais de uma vez, tratando-se de poliandria de acordo com Drummont (1984), Svard e Wiklund (1989), Wiklund et al. (1993) e Wedell, Wiklund e Cook (2002). Com relação a variação na quantidade de ovos nas folhas de manacá de cheiro do interior do cesto telado e da natureza deve ser em decorrência da pequena quantidade de ramos da planta hospedeira e do pouco espaço que as borboletas tiveram no interior do cesto telado, assim as fêmeas depositaram um maior número de ovos por folha a fim de garantir a perpetuação da espécie, enquanto que na natureza a postura de um ovo por folha previne a predação ou parasitismo dos ovos que se encontram próximos uns dos outros e a quantidade de folhas é muito maior do que no cesto telado e assim propiciam a manutenção da população. Foi possível verificar que a reprodução em Methona themisto é muito mais ativa no verão e primavera do que inverno e outono em que diminui o número de acasalamentos e as lagartas não conseguem sobreviver a baixas temperaturas. Isso foi observado também em outras pesquisas, onde de acordo com Vasconcellos-Neto (1980) a tendência dispersiva dos Ithomiinae é mais acentuada no verão, principalmente em regiões com clima sazonal.

\section{CONCLUSÃO}

A pesquisa possibilitou concluir que o ciclo de vida da borboleta Methona themisto é relativamente rápido e é possível o acasalamento e a corte no interior do cesto telado com área de 61,25 centímetros cúbicos e postura de ovos nas folhas dos ramos de manacá-decheiro durante 0 ano todo, não sendo afetada pelas variações sazonais, portanto, essa espécie apresenta viabilidade para criação em borboletário, visando a preservação da espécie e a Educação ambiental.

\section{REFERÊNCIAS}

BECCALONI, G.W.; GASTON, K.J. 1995. Predicting species richness oF Neotropical Forest butterfies: Ithomiinae (Lepidoptera: Nymphalidae) as indicators. Biol. Conserv. 71(1):77-86

BUZZI, José Zundir. Entomologia didática. 4. ed. Curitiba: UFPR, 2002.

BOGGS, C. L.; GILBERT, L. E. 1979. Male contribution reproduction in butterflies: evidence for transfer of nutrientes at mating. Science, New York, 206: 83-84

LIMA, Ângelo Moreira da Costa. Insetos do Brasil. $5^{\circ}$ tomo, Capitulo XXVIII, Lepidopteros. Escola Nacional de Agronomia, Série Didática, № 7, 1945.

DEVRIES, Philip James. 1987. The butterflies of Costa Rica and their natural history. Princeton University Press, New Jersey

DRUMMOND, B. A. 1984. Multiple matings and sperm competition in the Lepidoptera. In Smith RL (editor). Sperm competition and the evolution of animal mating systems. London: Academic Press. p. 291-370

FRANCINI, R.B. 2010. História Natural das Borboletas do Vale do Rio Quilombo, Santos, SP. Edição do autor, Santos

GULLAN, P.J.; CRANSTON, P.S. 2007. Os insetos: um resumo de entomologia. São 
Paulo, Roca, III+456p

HEPPNER, J.B. 1991. Faunal regions and the diversity of Lepidoptera. Tropical Biology. Lep. 2(1):1-85

LAMY, Michel. Os insetos e o Homem. Instituto Piaget, Lisboa, Portugal, 1997, p. 144

LAMAS, G. 2004. Checklist: Part 4A. Hesperioidea-Papilionoidea. In Atlas of Neotropical Lepidoptera. (J.B. Heppner, ed.). Association for Tropical Lepidoptera/Scientific Publishers, Gainesville, p.1-439

MARQUES, Beatriz Ribeiro; CAMARGO, Flávio de Vasconcelos; LACERDA, Fábio Vieira. Estudo dos instares da borboleta Methona themisto (Família Nymphalidae, Subfamília Ithomiinae) No Município de Delfim Moreira-Mg. Revista Científica da FEPI, v. 6, 2014.

REIS, Ana Carolina Ferreira. Côrte em Lepidopteras e Fragmentação de Habitat. Monografia de conclusão do curso de Biologia do Centro Universitário de Brasília, DF, 2003.

RUSZCZYK, Alexandre; NASCIMENTO, E. S. Biologia dos adultos Methona themisto (Hübner, 1818) (Lepidoptera, Nymphalidae) em praças públicas de Uberlândia, Minas Gerais, Brasil. Revista Brasileira de Biologia. v. 59, n. 4. p. 577 - 583. 1999.

SBORDONI, V.; FORESTEIRO, S. Butterflies of the World. New Book, New York, USA, 1984, p. $166-173$

SILVA, Gabriela Corso da. Diversidade de borboletas Nymphalidae na Mata Atlantica do Parque Municipal da Lagoa do Peri, Florianopolis, SC. 2008. 34f. Trabalho de conclusão do Curso de Ciências Biológicas - Universidade Federal de Santa Catarina, Florianópolis, 2008 de Santa Catarina, Florianópolis, 2008.

SOUZA-JUNIOR, Gilmar. Avaliação da viabilidade de Methonathemisto (Lepidoptera: Nymphalidae) para criação em borboletário. Trabalho de Conclusão de Curso, Universidade Estadual de Maringá, Maringá, PR. 2017.

SVARD, L e WIKLUND, C. 1989. Mass and production rate of ejaculates in relation to monandry/polyandry in butterflies. Behav Ecol Sociobiol 24: 395-402

TRIPLEHORN, C. A.; JONNSON, N. F. Estudo dos insetos. 7. ed. São Paulo: Cengage Learning, 2011.

VASCONCELLOS-NETO, J., 1980, Dinâmica de Populações de Ithomiinae (Lepidoptera: Nymphalidae) em Sumaré, SP. Tese de Mestrado, Universidade Estadual de Campinas, Campinas, SP, p. 206

WEDELL, N.; WIKLUND, C.; COOK, P. A. 2002. Monandry and polyandry as alternative lifestyles in a butterfly. Behaviora Ecology 13: 450-455

WILSON, E.O. 2003. Biodiversity. National Academy Press, Washington.

WIKLUND, C., KAITALA, A., LINDSFORS, V. e ABENIUS, J. 1993. Polyandry and its effect on female reproduction in the green-veined White butterfly (Pieris napi L.). Behavioral Ecology and Sociobiology, 33: 25-33 
